\title{
Bernstein and the Kantian antinomies of reason
}

\section{Zain Davis}

\begin{abstract}
In this paper I draw inspiration from Slavoj Žižek's (1993) deployment of Kant in his analysis of ideology in order to show that Basil Bernstein's theorising of education, specifically concerning the universal-particular dialectic, entails a series of discursive gestures that might productively be described in terms of Kant's antinomies of reason. The inscription of discursive resources akin to the Kantian antinomies in Bernstein renders the theory necessarily open despite its apparently totalising intent. I believe that the approach used here is more productive than engaging in the polemical bating and name calling that often emerges in discussions of relativistic versus universalist approaches to the production and uses of education theory.
\end{abstract}

\section{Introduction}

This commentary on Bernstein is conditioned by Slavoj Žižek's use of the work of Kant in his exhortation for us to "tarry with the negative" (Žižek, 1993) in the face of rampant relativism that besets much of contemporary philosophical and social scientific argumentation. Kant's tarrying with the negative entailed a radicalisation of the critique of traditional metaphysics mounted by Hume and the empiricists. Rather than reassert rationalist metaphysics in the face of the empiricist attack, Kant accepted Hume's criticisms and ended up demonstrating that knowledge was necessarily incomplete, but he did so without having to sacrifice universality (Kant, 1994, 1996, 2000).

In the field of education, Moore and Muller (1999) offer an interesting critical engagement with what they refer to as the "Discourse of "Voice" and, more generally, of postmodern accounts of knowledge. They argue that the "Discourse of "Voice" ' is little more than a self-defeating position-taking strategy that weakens the production of knowledge when taken seriously. For Moore and Muller, the 'Discourse of "Voice"' is aligned with 


\begin{abstract}
approaches that question epistemological claims about the objectivity of knowledge (and the status of science, reason and rationality, more generally) [and which] adopt, or at least favour or imply, a form of perspectivism which sees knowledge and truth claims as being relative to a culture, form of life or standpoint and, therefore, ultimately representing a particular perspective and social interest rather than independent, universalistic criteria. They complete this reduction by translating knowledge claims into statements about knowers. Knowledge is translated into knowing and priority is given to experience as specialised by category membership and identity. [. . .] Today, the most common form of this approach is that which, drawing on postmodernist and poststructuralist perspectives, adopts a discursive concern with the explication of 'voice'. (Moore and Muller, 1999, pp.189-90)
\end{abstract}

What Moore and Muller begin to make clear in their discussion is the presence of an impasse in curriculum theory in the form of an opposition between knowledge (in its concern with the production of universal statements) and morality (in its concern with the existential specificity of individuals). In establishing their argument, Moore and Muller appeal primarily to the Bernsteinian distinction between horizontal and vertical discourses - a strategy that I have commented on elsewhere (Davis, 2003).

I believe that one can address the concerns of Moore and Muller by siding with the "discourses of voice", approaching Bernstein as a typical instance of the type of totalising theory such discourses rail against, yet demonstrate that, despite its totalising intent, the theory remains necessarily open.

\title{
Bernstein and the discursive gap
}

The arrival, in Basil Bernstein's theorising, of the pedagogic device (Bernstein, 1990, 1996) with its explicit elaboration of the notion of a discursive gap, announces the completion of the formalisation in the theory of a structure that takes cognisance of the entanglements reason gets into with itself when it attempts to produce universalising statements. Perhaps it will come as a surprise to Bernstein cognoscenti that I turn to Immanuel Kant rather than remain within Bernstein's discussion of internal and external languages of description to address the notion of the discursive gap. My interest here is primarily focussed on the initial formulation of the notion in order to draw out the similarities between general features of Bernstein's methodology and Kant's discussion of the antinomies of reason. Later I shall return to the discussion of the discursive gap in the context of languages of description to show how it can be rendered in Kantian terms. Of course, 
nowhere in his corpus of work does Bernstein directly discuss Kant, but it is perhaps due to Bernstein's fidelity to Durkheim that Kant nevertheless insists in Bernsteinian theory (see Durkheim, 1953).

There is, however, an additional reason for appealing to Kant, and that is to bring a measure of coherence to the use of the notion of the discursive gap as expressed in Bernsteinian theory. Bernstein tends to deploy the term discursive gap in a number of different contexts. First, the discursive gap is used to speak about the indirect relation of knowledge to its material base. Second, it is employed to distinguish between order and disorder at the level of knowledge. Third, at the level of the semantic, it is used to mark the discontinuity between that which is given to us in sensible intuition ('the material') and the transcendental ('the immaterial'). Fourth, as I drew attention to above, between two orders of truth in the context of research, the first being that of the conformity of knowledge to its object (external language of description) and the second, the conformity of knowledge to itself (the internal language of description). With such various uses of the term it might be better to refer to $a$ discursive gap rather than the discursive gap since the notion of a gap is used to connect and distinguish different relations in each of the instances of its use described here.

\section{The Kantian antinomies of reason}

In all three of Kant's critiques (of pure reason (Kant, 1994), of practical reason (Kant, 1996), and of judgement (Kant, 2000), he stumbles up against the paradoxes that beset the universal. In relation to pure reason, the attempt to use categories to capture that which is beyond finite experience as we consider the universe as a whole, produces the universe as, simultaneously, finite and infinite and as a totalising causal network that nevertheless contains free beings. In relation to practical reason Kant finds that, in formal terms, evil coincides with the good if evil is chosen on the basis of principle rather than stemming from pathological impulses. In the synthesis of pure and practical reason, the judgement, Kant discovers that the intersection of beauty and purpose/teleology produces the sublime: that which is neither beautiful nor purposeful, but rather suprasensible; in short, the moral law. However, the sublime, under the aspect of beauty, presents the law in its pacifying function, while under the aspect of teleology it assumes a ferocious superego function, that of our a priori guilt before the law. 
In each of his critiques Kant discovers a rupture in the universal which is rendered as a pair of antinomic relations, the so-called mathematical and dynamical antinomies. First, the mathematical antinomy emerges when we are confronted with a series of phenomenal objects, given to sensible intuition which is finite. As soon as we attempt to extend our experience of the sensible beyond finite experience we employ transcendental categories that produce a contradiction: the universe emerges as both finite and infinite. Differently stated, all phenomena are subject to experience, but experience is necessarily incomplete. Next, the dynamical antinomy emerges when we consider that every phenomenon can be explained in terms of the universal chain of cause and effect (therefore, there is no such thing as freedom), however, phenomena cannot be fully accounted for without the hypothesis of a causality of freedom. In short, the mathematical antinomies are concerned with paradoxes generated by attempts at grasping the totality of phenomena, while the dynamical antinomies emerge from the necessity to posit the existence of noumenal entities beyond phenomena.

\section{The different faces of the discursive gap and its ontological priority}

So, what has any of this to do with Bernstein? It is my contention that, on the one hand, a series of Bernsteinian conceptual couples (classification and framing; recognition and realisation; voice and message; power and control all renditions, in different guises, of the relation between the what and the how), in fact index the inscription of the Kantian dynamical antinomies in the theory of symbolic control: all phenomena (knowledge; pedagogic subjects, procedures) are caught in the web of control (the universal causal nexus), but only on condition that there exists one who escapes, one who is able to generate a new chain of causes and effects. This structure is redoubled at the level of pedagogic discourse in the relation between the instructional and regulative discourses: while the (re)production of specialised knowledge is dominated by control (regulative discourse), the regulative cannot foreclose the possibility of an alternative regulation, producing in that way an alternative classification (with respect to knowledge, a reconfiguration of instructional discourse). Here we encounter Bernstein's version of Kant's dynamical antinomy. 


\section{The indirect relation between knowledge and its material base}

With the elaboration of the theory of the pedagogic device (Bernstein, 1990; 1996) the notion of the discursive gap announces Bernstein's version of Kant's mathematical antinomy: the discursive gap, as the marker of the indirect relation between meaning and its social base (the division of labour and the relations within the division of labour), ensures that the field of discursive production (of knowledge) is non-all (that is, necessarily incomplete). Bernstein's obfuscating language when discussing the effects of the discursive gap clearly points to the non-all nature of knowledge when he marks out the production of two classes of knowledge: the mundane and the esoteric, the thinkable and the unthinkable, knowledge of the possible and the possibility of the impossible.

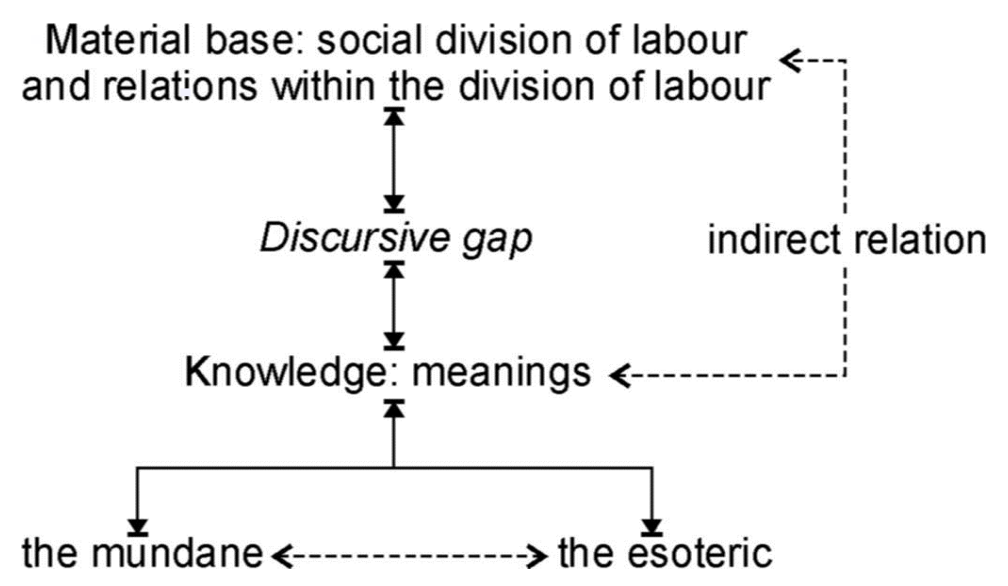

Figure 1: Schematic showing the location of the discursive gap as iitially formulated

Figure 1 is a schematic representation of Bernstein's initial formulation of the discursive gap, that is, the formulation in which he clearly locates the gap between the material base and knowledge: "the meanings which create and unite two worlds [the mundane and the esoteric] must always be meanings where there is an indirect relation to a specific material base ..." (Bernstein, 1996, p.44). The discursive gap is therefore not, at this point, the name for the distance between the two classes of knowledge, but rather the ontological condition for the very production of knowledge. From a Kantian perspective the relation between meanings and their material base are, of course, always indirect since we have no access to things in themselves. Like Kant, Bernstein 
recognises that the discursive gap (qua correlate to the mathematical antinomy) has ontological priority over the relation between the what and the how (correlate to the dynamical antinomy): first the indirect relation between knowledge and its material base, and then the antagonistic struggle for control of that indirect relation (that is, the structuring of the what and the how, starting from the elaboration of the content of the distributive rule of the pedagogic device):

I want to suggest that this gap or space can become (not always) a site for alternative possibilities, for alternative realisations of the relation between the material and the immaterial. The gap itself can change the relation between the material and the immaterial. This potential gap or space I will suggest is the site for the unthinkable, the site of the impossible, and this site can clearly be both beneficial and dangerous at the same time. This gap is the meeting point of order and disorder, of coherence and incoherence. It is the crucial site of the yet to be thought (Bernstein, 1996: p.44; italics in the original).

\section{Order and disorder in relation to the discursive gap}

In the above statement by Bernstein we can detect, in a first approach, a slide from the initial formulation of the location of the gap to one that now is, by definition, the empty intersection of order and disorder, the "meeting point [...] of coherence and incoherence," as well as the "site of the yet to be thought" (see Figure 2). If we translate these formulations into less obscure terms we might render them, collectively, as a proposition claiming that internal to knowledge itself we encounter a limit.

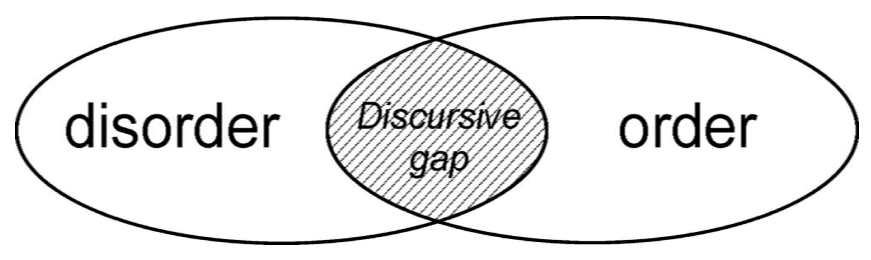

Figure 2: The discursive gap as the meeting point of order and disorder

Now there are various ways of reading this proposition. On the one hand I can read the limit simply as an historically-situated epistemological limit, as us not yet knowing everything there is to know. Such a formulation, with its implicit suggestion that perhaps someday, somewhere, we will arrive at 
complete knowledge is to be rejected for the reason that such knowledge will void the indirect relation between knowledge and its material base, and so nullify the difference between the material and the immaterial. Presumably, once the temporal limit is overcome, we will - in Kantian terms - have access to things-in-themselves and therefore the antinomies of reason will disappear. On the other hand, it can be argued that there is always a non-discursive excess of the material over the discursive (Dowling, 1998), necessarily rendering knowledge incomplete. This position is similar to that of the first case, but with the added sophistication of a trans-historical externally imposed limitation on knowledge: the non-discursive excess can never be eradicated, no matter the state of knowledge. As appealing as the latter reading of the proposition is at first blush, it too should be rejected. I reject it on the basis that it does not really get at the limit of knowledge. All it is doing is stating, in different terms, that we cannot know things in themselves, which is a fundamental Kantian axiom asserting that knowledge and the things of which it speaks belong to different ontological orders. Next, we can note that the nature of the internal limit of knowledge is not a simple externally imposed incompleteness but that knowledge itself has no limit. In other words, the ineradicable presence within knowledge of a 'site of the impossible' is the reason for the incompleteness of knowledge.

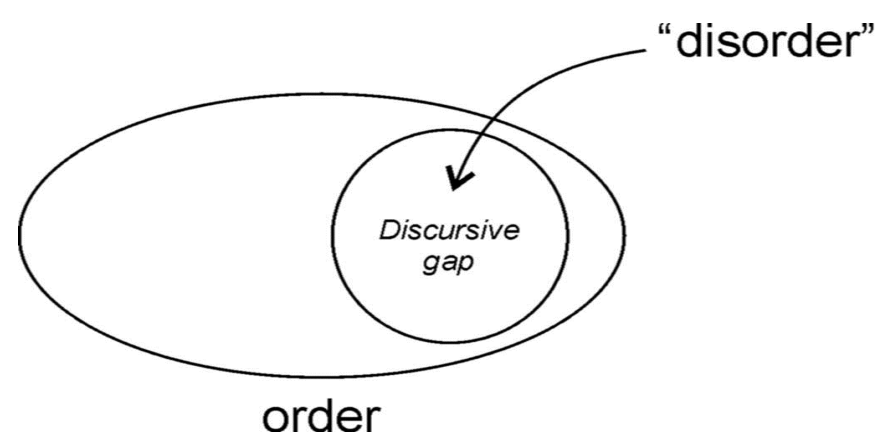

Figure 3: The discursive gap as the space of disorder within order

The apparently paradoxical result is then that the limit of knowledge is not a mere externally imposed limit generated by either the presence of an elusive 'non-discursive excess' or a historically experienced temporal limit, but rather that "stating the case in simplistic terms - the discursive itself necessarily 
knows no limit and so incessantly chatters on about its object. ${ }^{1}$ The formulation of the notion of the discursive gap as the 'meeting point of order and disorder' should therefore be grasped as locating the point of disorder entirely internal to order. Further, we should recognise that the term 'disorder' is already a means for rendering, in a pacifying way, the internal limit of knowledge as already a type of species of order. Figure 3 is a schematic of the result of our analysis of the relation between order (knowledge) and the discursive gap.

\section{The mundane, the esoteric, and the discursive gap}

Let me state upfront my contention that the discontinuity between the mundane and the esoteric in Bernstein cannot be rendered as a discursive gap located between the mundane and the esoteric. Neither can it be rendered as a discursive gap between the everyday and the academic at the level of pedagogic discourse. In Sohn-Rethel's (1978) terms, the material base (the social division of labour and relations within the division of labour) generates a 'fissure' between what he calls 'practical' (the mundane/the everyday) and 'theoretical' consciousness (the esoteric/the academic). The particular productive feature of the material base that Sohn-Rethel focuses on is the act of commodity-exchange, finding there the generative mechanism of 'two worlds'.

First, in his analysis of the commodity-form, Marx (1976, p.76) arrives at a definition of commodity fetishism as that of an inversion in which "a definite relation between men, that assumes, in their eyes, the fantastic form of a relation between things". In other words, social relations are expressed in the

A similar result is also apparent in Saussure's discussion of language: on the one hand we have the requirement for semantic closure that says that all signifiers must be presumed to be present in the form of a system of differential relations; that is, the synchronic aspect of language. On the other hand, language also requires that every signifier refers to another in a process of metonymic sliding from one signifier to another; that is, its diachronic aspect. Saussure's resolution of the tension between these two, apparently antagonistic principles of language, was to simply set to one side the diachronic and focus solely upon the synchronic. Postmodern deconstruction resolves the same tension by focusing on the diachronic, that is, on the infinite deferral of meaning as language is caught up in the incessant sliding of the signifier. 
value of a commodity, but in a strange way, in which value becomes detached from social relations and appears to be an intrinsic property of commodities in the form of a particular monetary value. Stated differently, while the value of a commodity is an effect of social relations within the division of labour, value is treated as though it inheres in the commodity outside of its relation to its social base. However, the key to commodity fetishism is to be found in the production of an equivalent which expresses the exchange-value of commodities: two commodities become equivalents only when one is rendered as though it was always-already, in itself, the equivalent of the other, which seems to be a property of it independently of its relation to the other. The most abstract realisation of such relations is, of course, money.

Second, let us now turn to Sohn-Rethel's (1978) discussion of real abstraction. Concluding from his detailed series of analyses of commodityexchange relations, Sohn-Rethel finds that two fundamental modes of consciousness result: 'practical' and 'theoretical'. However, he argues that the two modes of consciousness are effected by an abstraction that inheres in the act of the exchange of commodities. Here we should be careful to distinguish between the consciousness of the individual subjects engaged in commodity exchange and the act of exchange itself. It is the structure of the latter, according to Sohn-Rethel, that, while it is not thought, has the form of abstract thought. Real abstraction is the form of relations between commodities in the act of commodity-exchange; the individuals who relate as exchange agents are, for Sohn-Rethel, acting as 'practical solipsists' while the form of their exchanges is that of theoretical consciousness. What he is driving at here is that in the act of exchange, commodities are stripped of their specific use-values, their empirical qualities, and become abstract units of exchange-value, providing in that way the form of abstraction that is necessary for the elaboration of theoretical reason. This means that the form of theoretical reason is already staged at a moment external to such reason. In terms of my specific interests here, I can then argue that the distribution of the social good, ultimately structured as it is by commodity exchange, already presents in the form of a real abstraction a prefiguring of the form of consciousness that is 'theoretical'. In other words, the pathological activity of the subject caught up in the act of exchange is the ground for the generation of the transcendental subject, the latter being the support of the web of $a$ priori categories. 


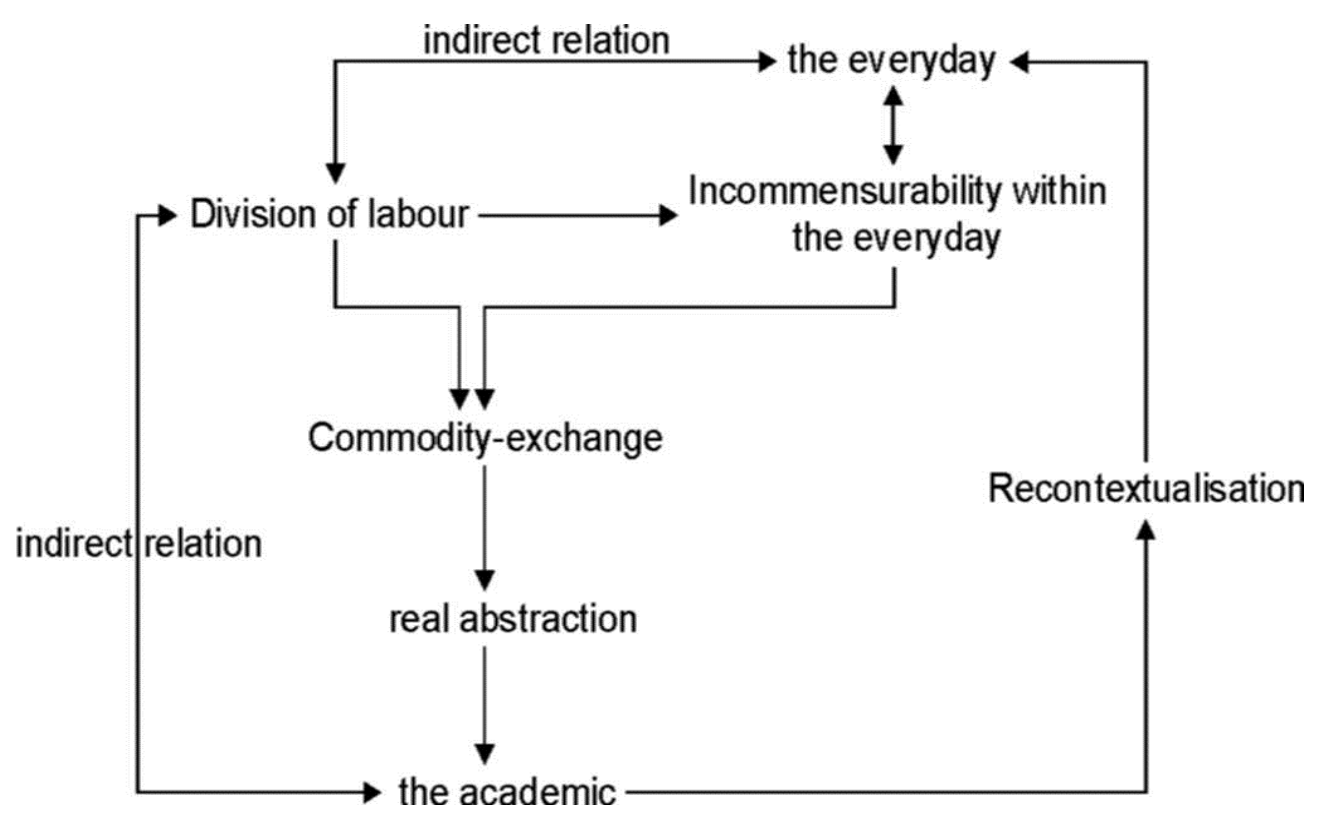

Figure 4: The place of incommensurability in the relation between the everyday and the academic

The irony of this result should not be overlooked: the circulation of positive contents grounds that which is formally independent of all positive contents! So much then for the simple version of the argument on the incommensurability of the everyday (the mundane) and the academic (the esoteric). Let me explain. Real abstraction is the name for the gathering together of the radically heterogeneous needs, desires and dispositions of subjects populating the division of labour, through commodity-exchange, into a system of general equivalents that provides the form for theoretical reason. The first encounter with incommensurability is situated at the level of the clash of heterogeneous needs and so forth of social subjects. The 'solution' to that fundamental incommensurability is the generation of an abstract, general equivalent in the act of commodity-exchange. The 'general form of thought' which is thereby produced is therefore already an amelioration of social incommensurability. In other words, the academic (universal knowledge), which is the thought derived from the real abstraction qua form of thought at the level of commodity-exchange, is a solution to the incommensurability internal to the everyday, returning to the everyday in a recontextualised form embedded in the administration of social life, technologies and so forth.

Figure 4 shows a simplified representation of the place of incommensurability. 


\section{The discursive gap and languages of description}

In an interview published in 1999, Bernstein used the notion of the discursive gap to clarify a methodological point on research practice (Bernstein and Solomon, 1999, p.275):

\footnotetext{
There [...] must be a discursive gap between the rules specified by [a] model and the realisation rules for transforming the information produced by the something [that is, the object of research]. This gap enables the something, so to speak, to announce itself, it enables the something to re-describe the descriptions of the model's own realisation rule and so change. (Italics in the original.)
}

It would appear that researchers are drawn to the representation of the notion of the discursive gap as presented in the above extract, preferring to avoid Bernstein's more obscure formulations of that notion in the context of his discussion of the distributive rules of the pedagogic device (in Bernstein, 1990, 1996). The use of the notion of the discursive gap in Bernstein and Solomon (1999) is that first formulated in the context of Bernstein's discussion of languages of description (in Bernstein, 1996) and as elaborated on by Dowling (1998). In their discussion of the growth of knowledge in the field of the sociology of education, Moore and Muller (2002) also appeal to the notion of the discursive gap as formulated in the context of the discussion of languages of description but remain silent on the earlier formulation of the notion.

Bernstein (1996, p.135) defines a language of description as "a translation device whereby one language is transformed into another". He goes on to distinguish between "internal and external languages of description". The difference between the two is the following: "The internal language of description refers to the syntax whereby a conceptual language is created" while an external language of description refers to the syntax whereby the internal language can describe something other than itself' (op.cit., p.136). The selection of theoretical referents that inform the production of the internal language of description is done in 'dialogue' with the empirical specificity of the object(s) of research. Once the internal language of description has been constructed the researcher needs to produce the external language, the work of which is to "construct what is to count as empirical relations and translate those relations into conceptual relations. A language of description constructs what is to count as an empirical referent, how such referents relate to each other to produce a specific text, and translate these referential relations into 
theoretical objects or potential theoretical objects. [. . . A language of description, from this point of view, consists of rules for the unambiguous recognition of what is to count as a relevant empirical relation, and rules (realisation rules) for reading the manifest contingent enactments of those empirical relations" (op.cit., pp.136-7). At this stage it might help to reproduce a diagrammatic representation of the notion of a language of description from Dowling's discussion of languages of description (see Figure 5).

From the theoretical referents, in dialogue with the empirical specificity of the object of research, we produce a series of theoretical propositions. The external language of description proper is constituted by a model, derived from the theoretical propositions, as well as recognition and realisation rules for the identification and interpreting of data, which must be such that the model can grasp the data. However, it has to be borne in mind that the recognition and realisation of data always closes down the initial openness of the information by restricting its semantic potential - the model cannot exhaust the empirical because the latter, argues Dowling (1993, 1998), represents a material excess with respect to the discursive (the model). This is why data is shown to reside in a 'discursive gap', which is a 'methodological space' between that which is internal to the external language of description and that which is internal to it. 


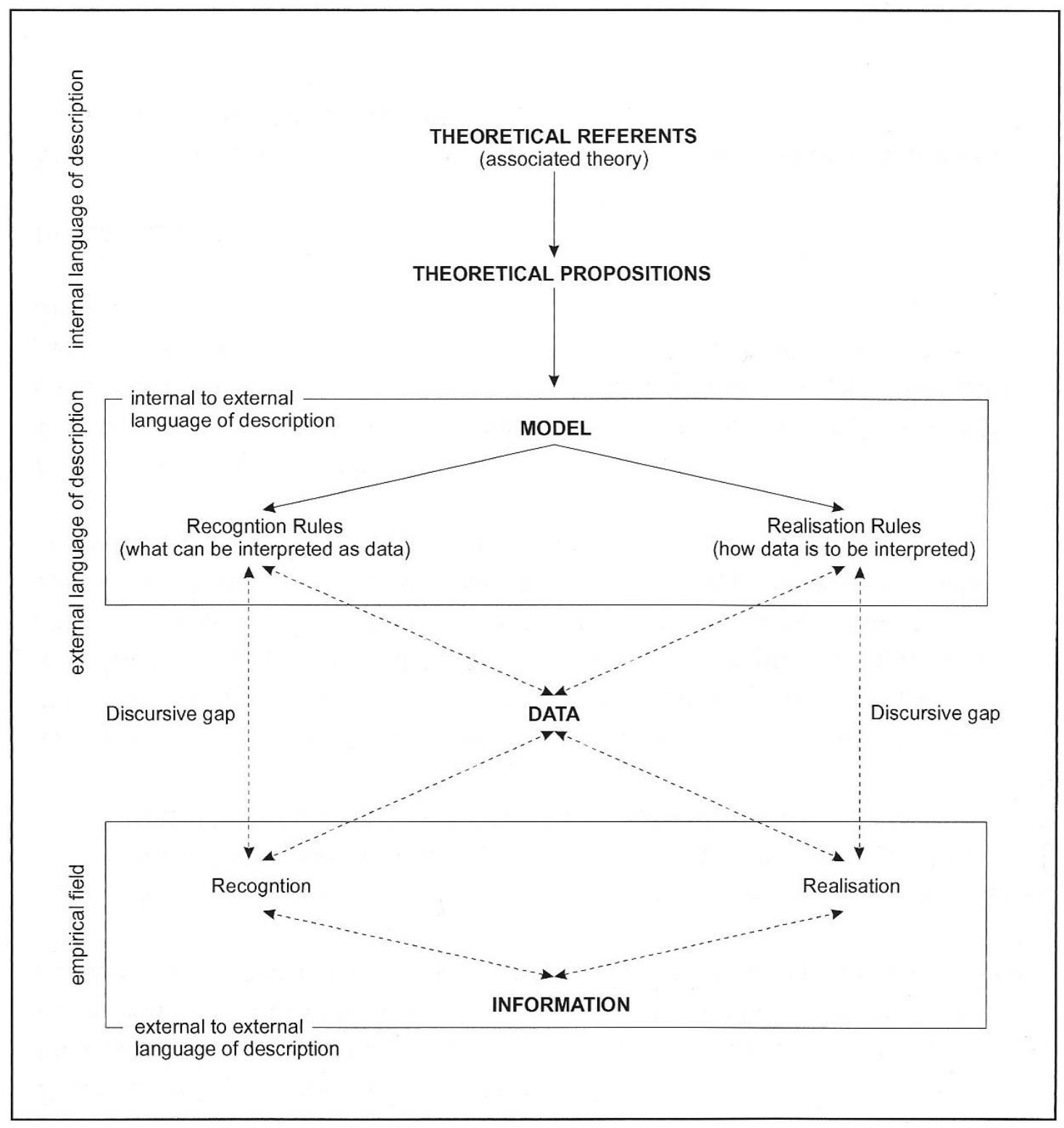

Figure 5: Schematic for a language of description (Dowling, 1993, p.88)

Bernstein's distinction between internal and external languages of description is in effect an acknowledgement that two orders of truth are always operative in the generation of knowledge. ${ }^{3}$ On the one hand the question of truth arises in considerations of the conformity of knowledge to its object. For Kant, this

3 In this Section I rely heavily on the analysis of Kantian thought in relation to Lacanian psychoanalysis produced by Alenka Zupančič (see Zupančič, 2000). 
aspect falls under the transcendental analytic of pure reason. In Bernstein's discussion, it is the function of the external language of description, which is the mediator between the internal language of description and the object of research. A different criterion for truth is produced by the question of the conformity of knowledge with itself. In other words, we also have a criterion for truth concerned with the internal consistency of knowledge. Here truth is to be found at the level of the internal articulation of signifiers rather than at the level of the relationship between the chain of signifiers and things understood as simply external to it. The place of this latter criterion in Bernstein's discussion of languages of description is that of the internal language of description. Once again we arrive at the limit of knowledge: the articulation of relations between the signifiers is, in principle, limitless, so that truth at this level, which Kant situates under the transcendental dialectic, is not-whole for the reasons discussed earlier.

Kant refers to the criterion demanding the conformity of knowledge with itself as the "formal criterion of truth" and argues that it is necessary for the evaluation of any statement whatsoever. In other words, the transcendental dialectic enjoys primacy. Interestingly, Bernstein arrives at a similar position, in which the internal language of description is primary: "the theory, however primitive, has always come before the research. Thus by the time a piece of research has been initiated the theory has already been subject to conceptual clarification as it engages the empirical problem. And by the time it has finished there have been further conceptual developments" (Bernstein, 1996, p.95; italics in the original).

The criterion requiring the conformity of knowledge to its object is referred to by Kant as the 'logic of truth', and that requiring the conformity of knowledge to itself, the 'logic of illusion'. Here illusion is not to be understood as the false representation of the truth. Rather, it is situated at an entirely different level from the criterion of the conformity of knowledge to its object. The 'illusion' is that which appears in the place of nothing, which, as I argued in Section 3.2, renders the internal limit of knowledge as 'disorder' and thereby already begins to produce order ex nihilo. Dialectical illusion "involves deception by the simple fact that it is" (Zupančič, 2000. p.66; italics in the original).

So, from my perspective, the discursive gap in the context of languages of description is nothing other than the Bernsteinian name for the distinction 
between the criteria for truth that pertain the transcendental analytic and transcendental dialectic.

\section{The pedagogic device and the antinomies of reason}

Finally, we can recognise that the Bernsteinian correlates to Kantian pure reason and practical reason, as well as the correlate to Kant's judgement are written into the theory of the pedagogic device. The object of pure reason is to complete the universal causal nexus in an effort to extend experience beyond the sensible. Here contemporary physics perhaps provides us with a suitably disturbing example of the distinction between the sensible and the intelligible: while quantum mechanics can be grasped as intelligible (as an internally consistent theory), as soon as we attempt to incorporate its results into the functioning of our everyday reality we experience a sense of a loss of reality; that is, quantum mechanics cannot be grasped in sensible intuition. At the level of pedagogic discourse, Bernstein's instructional discourse is that which connects us to the intelligible. Next, practical reason in Kant concerns the ethical and the relation of the subject to the moral law. In Bernstein's terms, the regulative discourse qua rules of social order are correlative to Kant's practical reason and it is here, at the level of the regulative discourse, that a space opens up for the possibility of an ethical pedagogic act. ${ }^{4}$ What is not as explicit in Bernstein as it is Kant, is that the moral law takes two forms: on the one hand, that of a pacifying function and, on the other, of a form directed at the enjoyment of the pedagogic subject: where you are ignorant, you enjoy and so escape the moral law (and therefore are a priori guilty). Finally, Kantian judgement, the synthesis of pure and practical reason, is rendered in Bernsteinian terms as the evaluative rule; that is, the principle structuring pedagogic judgement.

With reference to the definition of pedagogic discourse, I argue that the relation between the what and the how structures the relation between the instructional discourse and the regulative discourse along the lines of the relation between pure and practical reason, each with its own particular

During a session of his seminar at the University of Cape Town (Bernstein, 1994; 1997) Bernstein was asked by a participant if an ethical pedagogic act was possible. It is interesting that in his response Bernstein presented an example directly at the level of the regulative discourse: construct a task for the student to engage with that begins to reveal the principles of their regulation. 
realisation of the antinomies of reason. With respect to the instructional discourse the antinomies emerge as we move from the sensible to the intelligible; with respect to the regulative discourse, the antinomies emerge from the two forms of the moral law (its pacifying function versus its ferocious superego function) and from the possibility of an ethical act qua momentary suspension of the regulative, so producing a new configuration of the regulative.

With regard to the esoteric, Bernstein makes the empirically sound claim that access to the unthinkable is generally reserved for the upper reaches of the education system (knowledge production):

[T]he control of the unthinkable lies essentially, but not wholly, in the upper reaches of the educational system. This does not mean that the unthinkable cannot take place outside of the educational system, but the major control and management of the unthinkable is carried out by the higher agencies of education. On the other hand, the thinkable in modern complex societies is managed by secondary and primary school systems. (Bernstein, 1996, p.43; italics in the original.)

However, it is my contention that the essential difference between the two classes of knowledge resides in their respective occulting (the mundane) and revelation (the esoteric) of the not-whole character of knowledge.

\section{Concluding comments}

If it is indeed the case that Bernstein's theoretical work proceeded in a manner that effectively inscribed the antinomies of reason at every level of the theory in the relation between the what and the how and in the guise of the ever-present spectre of the discursive gap, then the theory cannot be totalising. Ironically, it is in the terms of apparently totalising theories like that of Bernstein rather than in the increasing proliferation of 'voice discourses' (Moore and Muller, 1999) that education can be theorised in a manner that keeps open a genuine path of approach to the 'unthinkable'. 


\section{References}

Bernstein, B. 1990. Class, codes and control, Volume $1 V$ : the structuring of pedagogic discourse. London: Routledge.

Bernstein, B. 1994. The First Bernstein Seminar at the University of Cape Town. (Audio). Cape Town: University of Cape Town.

Bernstein, B. 1996. Pedagogy, symbolic control, and identity. London: Taylor \& Francis.

Bernstein, B. 1997. The Second Bernstein Seminar at the University of Cape Town. (Audio). Cape Town: University of Cape Town.

Bernstein, B. and Solomon, J. 1999. 'Pedagogy, identity and the construction of a theory of symbolic control': Basil Bernstein questioned by Joseph Solomon. British Journal of Sociology of Education, 20(2): pp.265-79.

Davis, Z. 2003. Bernstein avec Lacan: Desire, jouissance and pedagogic discourse. In Trueit, D., Doll, W., Wang, H. and Pinar, W.F. (Eds), The internationalization of curriculum studies. New York: Peter Lang.

Dowling, P.C. 1993. A language for the sociological description of pedagogic texts with particular reference to the Secondary School Mathematics Scheme SMP 11-16. PhD. Thesis, University of London Institute of Education.

Dowling, P.C. 1998. The sociology of mathematics education: mathematical myths/pedagogic texts. London: Falmer Press.

Durkheim, E. 1953. Sociology and philosophy. Translated by J.G. Peristany. Chicago: Free Press.

Kant, I. 1994. Critique of pure reason. London: Everyman.

Kant, I. 1996. Critique of practical reason. New York: Prometheus Books.

Kant, I. 2000. Critique of judgement. New York: Prometheus Books.

Marx, K. 1976. Capital, Volume 1. Harmondsworth: Penguin. 
Moore, R. and Muller, J. 1999. The discourse of 'voice' and the problem of knowledge and identity in the sociology of education. British Journal of Sociology of Education, 20(2): pp.189-206.

Moore, R. and Muller, J.P. 2002. The growth of knowledge and the discursive gap. British Journal of Sociology of Education, 23(4): pp.627-637.

Žižek, S. 1989. The sublime object of ideology. London: Verso.

Žižek, S. 1993. Tarrying with the negative: Kant, Hegel, and the Critique of ideology. Durham: Duke University Press.

Zupančič, A. 2000. Ethics of the real: Kant, Lacan, London: Verso.

Zain Davis

University of Cape Town

zain.davis@uct.ac.za 